\title{
Itch evoked by the rubber hand illusion
}

\author{
Antoinette I.M. van Laarhoven ${ }^{1,2 *}$, Dieuwke S. Veldhuijzen ${ }^{1,2}$, H Chris Dijkerman ${ }^{3}$ \\ ${ }^{1}$ Institute of Psychology, Health, Medical and Neuropsychology Unit, Faculty of Social and \\ Behavioural Sciences, Leiden University, Leiden, The Netherlands \\ ${ }^{2}$ Leiden Institute for Brain and Cognition, Leiden University Medical Center, Leiden, The \\ Netherlands \\ ${ }^{3}$ Experimental Psychology/Helmholtz Institute, Utrecht University, Utrecht, The Netherlands.
}

* Corresponding author:

E-mail: A.vanlaarhoven@fsw.leidenuniv.nl (AvL) 


\section{Abstract}

It has been well-established that expectancies can influence itch intensity. It remains to be established whether psychological processes can lead to non-itchy input being perceived as itchy. The current study aimed to investigate whether healthy individuals perceive non-itchy tactile stimulation (rubbing) as itchy when having the illusion that an itch stimulus is applied (using the rubber hand illusion; RHI). Moreover, it was investigated whether this effect depended on psychological characteristics, including expectancies. In 36 healthy female volunteers, ownership over the rubber arm was induced in a standard RHI setup. After assessing the itch-inducing properties of merely rubbing, baseline itch was evoked by rubbing cowhage spicules (pruritogenic tropical bean particles) onto the left forearm. Cowhage was kept on the arm for some minutes (follow-up phase). Similarly, cowhage was subsequently applied onto the rubber arm, while the participant's concealed right arm was simultaneously rubbed without cowhage. Mean (mean=0.8, $\mathrm{SD}=1.1$ ) and peak itch (mean=1.3, $\mathrm{SD}=1.4)$ significantly differed from zero $(t=5.74, p<0.001$ and $t=6.89, p<0.001$, respectively). Expectations did not mediate the effect, but self-reported attention to itch (PVAQ-itch) was positively associated with itch during follow-up. Low levels of itch were induced using the RHI paradigm, demonstrating the role of psychological factors in itch perception.

Key words: rubber hand illusion; itch; pruritus; alloknesis; hyperknesis; sensitization; attention; attentional bias; dot-probe task; expectations 


\section{Introduction}

Itch signals potential bodily harm; hence itch has a nocifensive function. This function is often impaired in chronic itch conditions, for instance, as a consequence of skin conditions like atopic dermatitis ${ }^{1,25,28}$. Patients' chronic itch symptoms are often only moderately associated with clinically assessed disease severity ${ }^{15,49}$. In fact, peripheral and central sensitization are assumed to play a role in the amplification of itch signals as a result of neuroplastic changes. Phenomena characteristic to sensitization are alloknesis, defined by "an abnormal sensory state where stimuli that do not ordinarily evoke itch (such as the light touch of clothing) cause itch", and hyperknesis, defined by "enhanced itch to normally itch-provoking stimuli or lowered itch threshold to a given stimulus" ${ }^{1}$. In the field of pain, which is most closely related to itch ${ }^{51}$, allodynia and hyperalgesia are their respective equivalents. Psychological processes can contribute to sensitization processes, for instance, via cognitive processes such as attention and expectancies, that centrally modulate itch processing and, consequently, itch perception $^{29}$.

Preliminary evidence in the field of itch indicates that patients with chronic itch may display more attention (called attentional bias, AB) towards (visual) itch stimuli than control stimuli ${ }^{19,30}$, although patients may not differ from healthy controls ${ }^{30}$. Also, more self-reported attention towards itch has shown to be associated with increased itch sensitivity - this has only been investigated in healthy females thus far ${ }^{26,29}$. More robust evidence is found in the field of pain, showing that patients generally have an $\mathrm{AB}$ towards pain stimuli, presumably primarily because of difficulties disengaging attention from pain ${ }^{7,14,48}$ More attention to pain is also associated with more pain and -related disability (e.g., ${ }^{43}$ ). Speculatively, in line with these findings for pain, difficulty disengaging attention from itch may potentially also be involved in enhanced itch perception.

Negative expectations (e.g., of high itch) have repeatedly been demonstrated to aggravate itch responses ${ }^{9}$. For instance, patients with $\mathrm{AD}$ experienced more itch from saline when they expected it to be an allergen than when they knew it was a control solution ${ }^{39}$. Various studies in healthy individuals overall demonstrated that negative expectations can worsen itch ${ }^{9,36}$. Most of these studies induced itch expectations by means of instructing the participant what to expect (verbal suggestion), often in combination with the (repeated) pairing of high itch levels and a certain cue (conditioning) ${ }^{9}$. To our knowledge it has not been investigated whether expectations of itch can lead to the perception of itch for non-itchy stimuli, in line with the process of alloknesis.

The interaction between psychological and physical processes, for instance the role of attention and expectations in the perception of non-itchy stimuli as itchy, can be readily studied using the rubber hand illusion (RHI) paradigm. By synchronous tactile stroking, the rubber hand can become "embodied" or "owned", i.e. experienced as belonging to self ${ }^{10}$. Expectations play a key role here, as just the expectation of touch - without the actual touch - suffices to induce ownership ${ }^{46}$. Moreover, larger wheal and flare responses were found when applying histamine to the participants' concealed arm in conjunction with an embodied rubber arm when compared to a condition in which the arm was not embodied ${ }^{5}$. Also, scratching a non-itching arm induced itch-relief of an itching arm when using a mirror, another illusion of ownership ${ }^{24}$. Next to this indirect support for the possibility to induce itch via the RHI, research into pain is more abundant. Previous pain research has demonstrated that mechanical stimuli on the own arm were perceived as more painful when observing an embodied rubber hand being simultaneously attacked ${ }^{6}$ or when it looked injured ${ }^{35}$. Moreover, physically threatening an embodied rubber hand was perceived and cortically processed as if the own hand was in danger - accompanied by a brain representation of a withdrawal response ${ }^{17}$. Expectations seem also to be able to modulate pain perception via the RHI, e.g., pain severity was decreased by applying a supposedly analgesic cream to the rubber arm $^{11}$. There are also indications that merely the induction of 
rubber hand embodiment can lower evoked pain levels, although evidence is equivocal ${ }^{18,35,37}$. Additionally, indirect evidence from other fields indicates that individual characteristics, such as mental imagery and cognitive intrusions, may be associated with negative expectancies and/or embodiment $^{4,34}$. All in all, it seems likely that itch can be induced via the RHI paradigm and that individual characteristics, including expectations and attention, probably play a key role. Yet, the RHI has not been applied to study itch.

The primary aim of the present study was to investigate whether healthy individuals can feel itch upon and after non-pruritic tactile stimulation when having the illusion of receiving an itch stimulation. Secondarily, the role of the individual's AB for itch (specifically attentional disengagement) and embodiment in itch evocation during the RHI was investigated. Additionally, it was explored whether expectations about itch mediate the relationship between experienced itch during baseline itch stimulation and the induced levels of itch during the RHI. Also explored was the association between the induced itch and self-reported attention to itch, mental imagery ability (for cutaneous perceptions), and the experience of cognitive intrusions by itch. We hypothesized that itch could be induced upon observing that an itchy substance is rubbed onto an embodied rubber arm when synchronously perceiving the rubbing sensation on the own arm. Moreover, more AB towards itch as well as better embodiment of the rubber arm was expected to be associated with increased itchperception.

\section{Materials and methods}

\section{Participants}

Thirty-six female volunteers (mean age 21.2 years with standard deviation $(\mathrm{SD})=2.4$, range 18 27 years) were included in this study. Criteria for inclusion were: 1) being female (because of the female appearance of the prosthetic arm used); 2) in the age range of 18 to 35 years (for homogeneity purposes of age distribution), and 3) having normal vision or corrected-to-normal vision by contact lenses. Exclusion criteria were: 1) having a condition associated with chronic itch, e.g., atopic dermatitis; 2) having (a history of) a neurological or psychiatric diagnosis, e.g., multiple sclerosis or major depression; 3) having disabilities in the upper body; 4) wearing glasses (due to eye tracking measurements during the attention task for itch), and 5) using $>3$ times / month drugs, e.g. cannabis, MDMA. The sample size was derived from a power calculation taking into account to test whether the average itch ratings during the RHI significantly differed from 0 (one-sided) with an alpha of 0.05 , a power of 0.90 , and an estimated medium effect size $\mathrm{d}$ of 0.5 .

\section{Design}

The study comprised a within-subjects design (see Fig 1; note that the RHI part and the part with the dot-probe task and self-report questionnaire were offered in counterbalanced order), in which each participant completed a 1) tactile procedure aimed at inducing ownership over the rubber arm;2) baseline cowhage application on the left arm; 3) repetition of the tactile ownership induction procedure, followed by a test of the rubber hand illusion in which cowhage was rubbed onto the rubber hand whilst the participant's hand was rubbed without cowhage; 4) dot-probe task to measure $\mathrm{AB}$ towards itch-related pictures; and 5) several self-reported questionnaires. The induction of alloknesis was considered successful when merely rubbing did not induce itch while itch was significantly evoked during the test of the RHI. The protocol was approved by the Psychology Research Ethics Committee of Leiden University (CEP19-0926/478). 


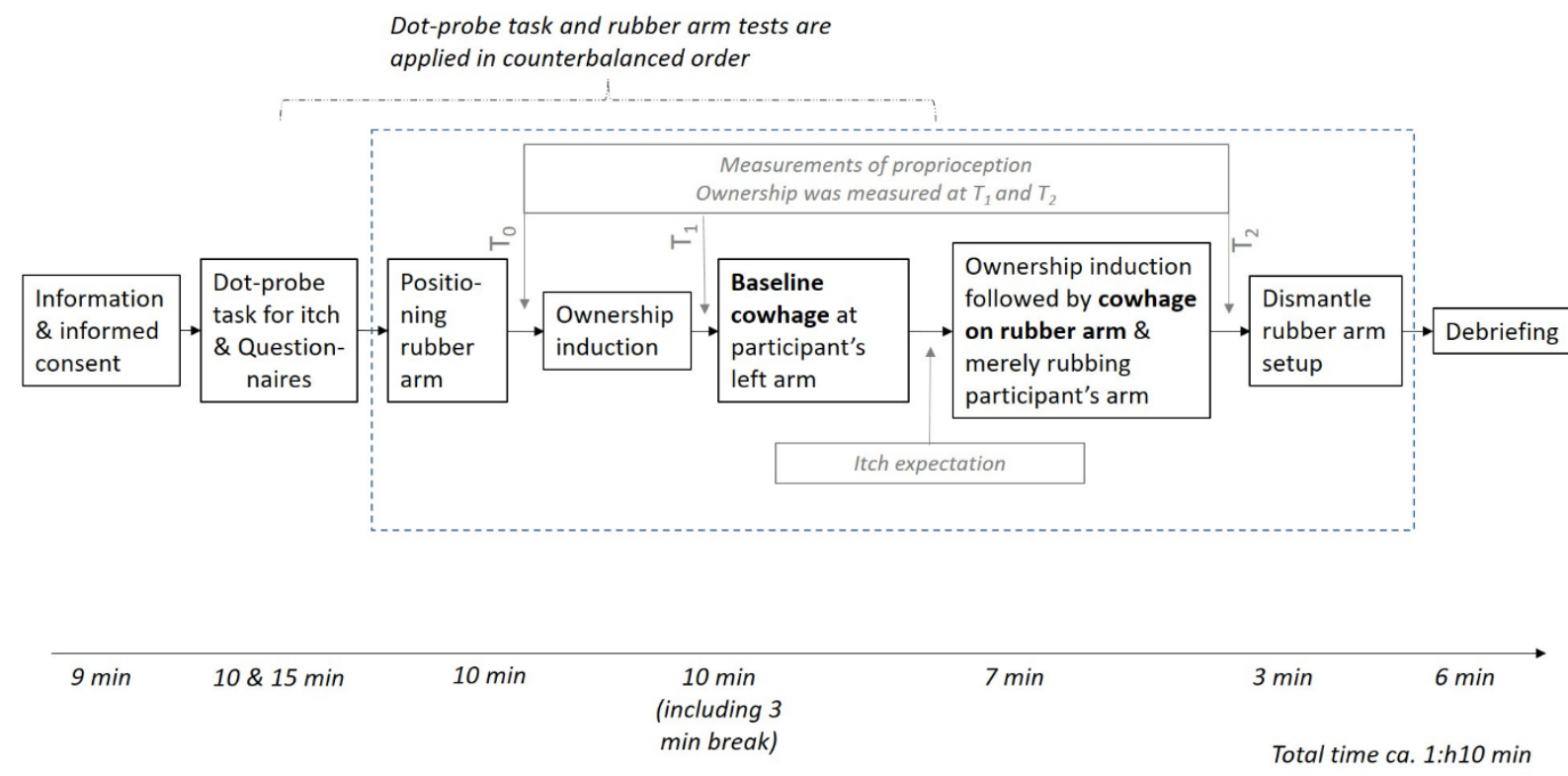

Fig 1. Design and timeline of the study. The order of the part with the cowhage inductions and the rubber hand illusion (dashed box) and the dot-probe task for itch as well as the questionnaires was counterbalanced.

\section{General procedure}

Participants were recruited by advertisements at the Faculty of Social and Behavioural Sciences of Leiden University, the Research software SONA systems Ltd (Tallinn, Estonia), and social media. When eligible in terms of in- and exclusion criteria, participants made an appointment to be tested. Upon arrival to the lab, participants were informed about the test procedures, whilst it was concealed that cowhage was in fact not applied to the participant's arm during the illusion. After verification of eligibility criteria, informed consents for participation in the study were signed by both the participant and researcher. Participants were also asked about their age, educational level, and dominant hand.

The participant started either with the procedure described in Cowhage-evoked itch followed by Rubber hand illusion or with the Dot-probe task for itch followed by the Questionnaires (except for the end questions that were always administered at the end). In the case that a participant's peak itch levels were $<1$ for the baseline cowhage application (i.e. cowhage non-responder), the experiment was aborted, and the participant was replaced by another participant (with a maximum of 10\% replacements; none of the participants were eventually replaced). Finally, participants filled out the end questions, they were debriefed, and compensated either financially or with psychology course credits (for first year students only).

\section{Cowhage-evoked itch}

Circa 40-45 cowhage spicules (hairy parts of the tropical bean mucuna pruriens) were counted using a Bresser microscope Advance ICD 10x-160x (Meade Instruments Europe GmbH \& Co. KG, Rhede, Westfalen, Germany) and negative grip tweezers (Dumont Tweezers Negative Action Style NS, Electron Microscopy Sciences, Switzerland). The cowhage application area was located on the volar side of the forearm, $5 \mathrm{~cm}$ ventrally from the wrist, which was demarcated using $1.25 \mathrm{~cm}$-width surgical tape (3M Transpore White; St. Paul, MN, US). To assess whether merely rubbing causes itch, the cowhage application area was gently rubbed by circular movements with the experimenter's 
fingertip for $45 \mathrm{~s}$. To induce itch, cowhage spicules were applied using the tweezers, which were gently rubbed onto the skin for $45 \mathrm{~s}$ with similar circular movements $\left(\right.$ e.g., $\left.{ }^{2,3}\right)$ and left on the skin for another $2.5 \mathrm{~min}$. Thereafter, spicules were removed by use of $3 \mathrm{M}$ Transpore White Surgical tape (2.5 cm width).

Participants rated the levels of itch every $15 \mathrm{~s}$ on a numerical rating scale (NRS) ranging from 0 (no itch at all) to 10 (worst itch imaginable) during the two phases of the cowhage application, i.e. during $45 \mathrm{~s}$ of rubbing and, while discontinuing rubbing, 2.5 minutes of keeping the cowhage on the skin / rubber arm. Urge to scratch was rated on an NRS from 0 (no urge to scratch at all) to 10 (worst urge to scratch imaginable) 0:45, 1:45, and 2:45 min after the start of cowhage rubbing. Two minutes after cowhage removal, the levels of itch and urge to scratch were assessed again. Additionally, expected itch was assessed using an NRS ranging from 0 (no itch at all) to 10 (worst itch imaginable) just before cowhage was applied during the RHI.

\section{Rubber hand illusion}

Participants placed their forearms with the ventral side facing upwards in a wooden box consisting of a small and a large compartment (as used in ${ }^{46,47}$ ). The backside of the box, i.e. the experimenter's side, displayed a ruler (see ${ }^{46,47}$ ). The right arm was positioned out of the participant's sight in the small compartment (the target position of the index finger was $68.3 \mathrm{~cm}$; in the experiment its average position eventually was $69.0 \pm 1.8 \mathrm{~cm}$ ). The left arm was positioned in the large compartment, where, after participants had closed their eyes for a moment, also the right-handed rubber arm was placed (the target position of the rubber arm's index finger was $54 \mathrm{~cm}$; in the experiment its average position eventually was $54.5 \pm 2.0 \mathrm{~cm}$, based on $n=35$ ). Participants wore a black apron to cover the blunt end of the rubber arm. They were instructed to keep focusing on the rubber arm during the entire experiment, except for when they were given other instructions (e.g., when they were presented the ownership subscale of the embodiment questionnaire).

\section{Proprioception measurement and tactile ownership induction}

A baseline measurement of proprioception $\left(\mathrm{T}_{0}\right)$ was carried out in which the participant indicated where she felt her right index finger. To this end, the experimenter moved a knitting needle along the backside of the wooden box (where the ruler was attached) from the corner towards the participant's right arm (note that the compartments were temporarily covered so the participant could not see the rubber arm nor the own arms) (see ${ }^{46,47}$ ). Next, participant's arm and the rubber arm were stroked synchronously for $90 \mathrm{~s}$ with two brushes according to the affective touch procedure described previously (ca. $3 \mathrm{~cm} / \mathrm{s}$ ) in order to induce ownership over the rubber arm ${ }^{46,47}$. Subsequently, proprioception was measured again using the knitting needle $\left(\mathrm{T}_{1}\right)$. How strongly the participant perceived the rubber hand as her own ("embodiment") was measured $\left(\mathrm{T}_{1}\right)$ by verbally administering the ownership subscale of the embodiment questionnaire (see Questionnaires).

\section{Cowhage application in the rubber hand illusion}

First, the application area was merely rubbed for $45 \mathrm{~s}$ (without cowhage). Second, participants were instructed that they would receive the itchy plant particles called cowhage. The baseline cowhage application on the left arm was conducted to be able to exclude non-responders (defined by NRS peak itch <1) and to give the participants an impression of how the itch stimulus felt. Another tactile ownership induction procedure (i.e. synchronous tactile stroking) followed. Immediately after, the rubber arm and the participant's right arm were rubbed synchronously, with the application of cowhage only to the rubber arm. Finally, proprioception and the ownership subscale of the 
embodiment questionnaire $\left(\mathrm{T}_{2}\right)$ were assessed again. The participant's apron was removed, and the participant was seated behind the computer to continue with either the dot-probe task or the end questions.

\section{Dot-probe task for itch}

The pictorial stimulus material for the dot-probe task had been validated and used previously $\left({ }^{8}\right.$; note that for the present dot-probe task only the 40 itch-neutral stimulus pairs were used but not the pain and negative stimuli). During a trial, first a fixation dot was shown in the middle of the screen for $500 \mathrm{~ms}$, followed by the presentation of the itch-neutral picture pair for $1250 \mathrm{~ms}$, and subsequently a target for at maximum $1500 \mathrm{~ms}$. The target consisted of a pair of dots that were either horizontally $(\bullet)$ or vertically $(:)$ oriented, and participants were instructed to respond to the orientation of the targets as quickly as possible using finger response buttons (Pushbutton Switch, SPDT, Off-(On)) connected to a serial response box model 200A (Psychology Software Tools Inc. Sharpsburg, PA, USA). The target disappeared upon button press. Every picture pair was presented 4 times (160 trials in total). Half of the trials displayed the itch stimulus and the target at a congruent location (e.g., both in the upper half of the screen) and the other half of the trials displayed the itch stimulus incongruently to the target location (e.g., the itch stimulus in the lower and the target in the upper half of the screen).

The task was conducted on a Dell Optiplex 3040 computer with an AOC I2475PXQU computer screen, using the software program E-Prime 3.0 (Psychology Software Tools, Sharpsburg, PA, USA). The participant's gaze on the itch and neutral pictures was measured during the task using a Tobii Pro X3-120 eye tracker (Stockholm, Sweden) with E-prime extension. Unfortunately, the eyetracking data had not been saved due to a programming error and could therefore not be analyzed nor reported. Participant's chin rested in a chin rest, positioned $61 \mathrm{~cm}$ from the computer screen. The dotprobe task took about 10-15 minutes to complete.

\section{Questionnaires}

The ownership subscale of the embodiment questionnaire (as used $\mathrm{in}^{46}$, with the slight adjustment that the word "hand" was replaced by "arm" in the current study), was administered to measure the subjective sense of ownership over the rubber arm. The questionnaire consisted of 5 items, e.g., "It seemed like I was looking directly at my own arm, rather than at the rubber arm" and "It seemed like the rubber arm belonged to me". A printed version of this subscale was shown on top of the wooden box to keep participants engaged in the illusion. Items were scored on a visual analogue scale from 1 (I totally disagree) to 10 (I totally agree) and scores were averaged to obtain the subscale score. The illusion was considered successfully induced when the participant scored at least a 7 (equivalent to the cut-off described $\mathrm{in}^{46}$ ). Cronbach alpha of this subscale was 0.90 at $\mathrm{T}_{1}$ and 0.95 at $\mathrm{T}_{2}$.

Imagination ability within the cutaneous domain was measured with the cutaneous subscale of the Questionnaire upon Mental Imagery (QMI-cutaneous) ${ }^{16,44}$. Items of the visual subscale were shown first to familiarize the participants with the type of questions. Participants were instructed to "visualize" (visual subscale, 5 items) or "feel" (cutaneous subscale, 5 items) specific images or objects and to rate them on the degree of clearness and vividness. For instance, for the visual subscale participants were asked to rate the degree of clearness and vividness of "the exact contour of face, head, shoulders and body" when thinking of a close relative or friend. For the cutaneous subscale the image of "feeling or touching" of "sand", "linen" or "the prick of a pin" were for instance rated. Each item was scored on a scale from 1 (perfectly clear and as vivid as the actual experience) to 7 (no image present at all, you only "knowing" that you are thinking of the object). The score of the cutaneous 
subscale was calculated by averaging the scores of the 5 items. The Cronbach alpha of this subscale was 0.71 .

Attention to itch was measured with the for itch adjusted Pain Vigilance and Awareness Questionnaire (PVAQ-I); original Dutch PVAQ ${ }^{41}$. It consisted of 16 items, e.g., "I focus on sensations of itch" and "I find it easy to ignore itch", scored on a Likert scale from 0 (never) to 5 (always). The total score was calculated by summing the scores while considering that 2 items were reversed keyed. The Cronbach alpha of the PVAQ-I was 0.82 .

The extent to which itch interferes with someone's cognitions was measured with the for itch adjusted Experience of Cognitive Intrusion of Pain scale (ECIP-I); original pain version ${ }^{4}$ ). It consisted of 10 items, e.g., "Itch intrudes on my thoughts". Ratings had not been recorded from 0 to 6 , but from 1 (not at all applicable) to 6 (highly applicable) due to a programming error. The Cronbach alpha of the ECIP-I was 0.94 .

The end questions inquired about $\mathrm{A}$ ) the degree of attentional distraction during the rubber arm illusion (NRS from 0 not at all to 100 completely); B) only when distracted >10 in question A): the reason for distraction was followed up by the answer options a) muscle pain in your arm(s), b) itch on a body part different from your arm, c) thoughts, for instance about private matters, d) other, namely; C) to what extent could you identify with the rubber arm (NRS from 0 not at all to 100 completely)?; D) only when identifying <90: what is the most important reason you could not completely identify with the rubber arm? Because of a) the skin color; b) the shape/position; c) the size; d) other, namely; E) When comparing the experience of itch on the left and right arm, did you feel more, equal or less itch during the second application, on the right arm, when compared to the first application, on the left arm? (much less / somewhat less / equal / somewhat more / much more); F) Do you have any further remarks?

\section{Statistical analyses}

Data pre-processing for the RHI included calculating the deviation in proprioception at the different measurement points by subtracting the perceived location from the actual location of the participant's right index finger ${ }^{47}$, followed by calculation of the proprioceptive drift (deviation scores at $\mathrm{T}_{1} / \mathrm{T}_{2}-\mathrm{T}_{0}$ ). A positive score reflects a drift in the direction of the rubber arm. For the dot-probe task, data on RT and accuracy were extracted from E-prime.

Four manipulation checks were carried out, to investigate whether 1) the baseline cowhage application evoked itch; 2) proprioceptive drift was in the direction of the rubber hand; 3) the participants felt ownership over the rubber hand; and 4) merely rubbing did not evoke itch. When manipulation checks failed, sensitivity analyses were carried out for the primary study outcome in a subgroup of the participants in addition to the main analyses on the entire sample. For the first manipulation check, in one-sample t-tests it was tested whether the average itch during the baseline cowhage application on the left arm both during the $45 \mathrm{~s}$ of cowhage rubbing and the 2.5 minutes follow-up (i.e. keeping the cowhage on the skin until removal) were significantly larger than 0 . Since only cowhage-itch responders (defined by peak itch for the baseline cowhage application equal to or larger than 1) continued the study after the baseline cowhage application, no sensitivity analyses were planned for this manipulation check. The second manipulation check entailed checking whether proprioceptive drift was in direction of the rubber hand. A repeated measures analysis of variance (RM-ANOVA) with simple contrasts tested whether there was a significant drift in proprioception at $\mathrm{T}_{1}$ and $\mathrm{T}_{2}$ as opposed to $\mathrm{T}_{0}$. In the case that the deviation (between the actual and perceived position of the hand) in proprioception was not significant, sensitivity analyses on the primary outcome were planned by excluding the subgroup that did not show a proprioceptive drift as well as comparing those participants who showed a significant change in proprioception with those who did not using a $t$-test. 
For the third manipulation check, the individuals' ownership over the rubber arm at $\mathrm{T}_{1}$ was checked on basis of the ownership subscale of the embodiment questionnaire. Sensitivity analyses on the primary outcome were planned for the group excluding those who scored below a 7 on this scale as well as comparing those participants who were embodied to those who were not, using a $t$-test. The fourth manipulation check verified whether merely rubbing did not induce itch. To this end, in a one sample t-test was tested whether the average levels of itch during the $45 \mathrm{~s}$ of merely rubbing (right before the supposedly administration of the cowhage on the rubber arm) differed from 0 . Sensitivity analyses were planned on the primary outcome by excluding those participants that felt itch from merely rubbing as well as comparing those participants who felt itch from merely rubbing to those who did not, using a $t$-test. Additional post-hoc sensitivity analyses included comparing the itch scores during merely rubbing to those during the supposed cowhage application in a RM-ANOVA with the withinsubjects factors time (itch assessment points during rubbing) and cowhage illusion (no / yes).

To answer the main research question whether itch was induced during the RHI, one sample ttests were conducted testing whether the average (primary outcome) and peak (secondary outcome) levels of itch during the rubbing phase of the cowhage application significantly differed from 0 . Posthoc paired sample t-tests were conducted to assess whether the supposed administration of cowhage during the rubbing phase of the RHI induced significantly more itch and urge to scratch than merely rubbing. Secondarily, it was tested whether the average and peak levels of itch during the 2.15 min follow-up phase of the cowhage application significantly differed from 0 . Additionally, the mean urge to scratch associated with the cowhage application during the RHI was explored similarly.

To test the secondary hypotheses whether there is an association between the experience of itch and $\mathrm{AB}$ towards itch (dot-probe task) as well as the level of embodiment of the rubber arm, correlation coefficients were calculated between the mean itch levels induced during the RHI and the AB-index for itch, the ownership subscale of the embodiment questionnaire and the proprioceptive drift (at both $\mathrm{T}_{1}$ and $\mathrm{T}_{2}$ ).

For the dot-probe task, a 2x2 RM-ANOVA was conducted with the within-subjects factors itch picture-position (upper/lower half of the screen) and the dot-position (upper/lower half of the screen). The average RT that were included in this analysis were based on correct trials and trials with RT > $150 \mathrm{~ms}$. Moreover, the criterion that at least $70 \%$ of the trials should be correct ${ }^{8,27}$ was applied on these data. Consequently, one participant had to be excluded due to an excessive number of errors ( $15 \%$ correct). Mostly because of the omission of all trials of this individual, in total $7.4 \%$ of the trials were excluded from the main analyses. In addition, an AB-index was calculated by subtracting the RT of the congruent trials from the $\mathrm{RT}$ of the incongruent trials $\left(\mathrm{RT}_{\text {incongruent }}-\mathrm{RT}_{\text {congruent }}\right)$. Reliability of the AB-index of the dot-probe task was assessed by calculating split-half reliabilities using the 'splithalfr' $\mathrm{R}$ package ${ }^{40}$. A Monte-Carlo splitting technique was used to estimate 5000 split-half samples for an estimation of the Spearman-Brown correlations over all samples. Both the median and IQR of the Spearman-Brown correlation coefficient were calculated.

Exploratorily, correlation coefficients between the experience of alloknesis (mean itch during the RHI) and the participant's mental imagery ability for cutaneous perceptions (QMI-cutaneous), selfreported attention to itch (PVAQ-I), and cognitive intrusions of itch (ECIP-I) were calculated. Correlation coefficients were also calculated between the proprioceptive drift and the self-reported ownership at $\mathrm{T}_{2}$. In principle, Pearson correlation coefficients were calculated for all these associations, except for variables that were not normally distributed, which were associated using Spearman correlation coefficients. A median split was carried out dividing the participants into a group of itch-responders and a group of itch non-responders on basis of the itch they experienced in the rubbing phase of the RHI. The responders and non-responders were subsequently compared on the measures of embodiment, their $\mathrm{AB}$ towards itch, as well as the self-report questionnaires. 
The possible mediating role of expectations was explored by mediation analysis with the Process Macro v3.5; model $4^{23}$. Here, the mean level of itch during the rubbing phase of the baseline cowhage application was the independent variable $(\mathrm{X})$, the mean levels of itch during the rubbing phase of the RHI the dependent variable (Y) and the itch expectations before the RHI the mediator variable. Likewise, mediation analysis was performed for the follow-up phase, with the mean levels of itch during the follow-up phase of the baseline cowhage application representing $\mathrm{X}$, and the mean levels of itch during the follow-up phase of the RHI representing Y.

Except for the reliability of the dot-probe task for which statistical analyses were conducted using $\mathrm{R}^{13}$, all analyses were run in SPSS 25.0 (IBM SPSS Statistics for Windows, Armonk, NY, USA). All values displayed are means \pm standard deviation (SD) unless stated otherwise. For all one sample and paired t-tests, log-transformation was performed in case of non-normality of variables. When log-transformation was ineffective in obtaining normal distribution, a bootstrapped t-test was performed with 5000 samples. As measure of effect size $(E S)$, partial eta squared $\left(\eta_{\mathrm{p}}{ }^{2}\right)$ was calculated for RM-ANOVAs (for the one-sample t-test, the ESs can be directly derived from the t-value and the $n$ and are therefore not reported here $)^{31}$. The Sidak-Holm correction was applied for the RM-ANOVAs when performing post hoc tests. The level of statistical significance was set at $p<0.05$.

\section{Results \\ Participants}

Of the participants ( $n=36), 92 \%$ was right-handed and $97 \%$ followed or had completed tertiary education. All participants had normal vision, of whom $83 \%$ without correction and $17 \%$ wore contact lenses. The protocol was explained in Dutch to $53 \%$ of the participants, and in English to the remainder. None of the participants reported having spontaneous itch at baseline.

\section{Manipulation checks}

The first manipulation check investigated whether the baseline cowhage application significantly induced itch (see Fig 2 for the NRS itch scores over time). The one-sample t-test demonstrated that the average itch evoked during the baseline cowhage application on the left arm during both rubbing $(2.5 \pm 1,9$; range 0.0 to 7.4$)$ and in the $2.15 \mathrm{~min}$ follow-up $(3.9 \pm 2.9)$ was indeed significantly larger than $0(t(35)=7.67, p<0.001$ and $t(35)=8.18, p<0.001$ respectively $)$. This also applied for the peak itch during rubbing $(3.0 \pm 2.3 ; t(35)=8.03, p<0.001)$ and in the follow-up $(5.3 \pm$ $3.1 ; t(35)=10.25, p<0.001)$. Also, the mean urge to scratch significantly differed from 0 during rubbing $(1.9 \pm 2.6$; log-transformed: $t(35)=6.10, p<0.001)$ and in the follow-up $(4.1 \pm 3.3 ; t(34)=$ $7.32, p<0.001$. Note, for one participant, these values were not recorded).

For the second manipulation check, the simple contrasts in the RM-ANOVA demonstrated that there was a significant proprioceptive drift (Table 1$)$ at both $\mathrm{T}_{1}\left(F(1,35)=51.77, p<0.001, \eta_{\mathrm{p}}^{2}=0.597\right)$ and $\mathrm{T}_{2}\left(F(1,35)=13.40, p=0.001, \eta_{\mathrm{p}}^{2}=0.277\right)$, indicating that as compared to the $\mathrm{T}_{0}$ measurement, the participants' sense of their right index finger was moved towards the position of the rubber hand at both time points.

For the third manipulation check, the ownership subscale demonstrated that $50 \%$ of the participants scored below the cut-off score of 7.0 on the ownership subscale of the embodiment questionnaire. Therefore, sensitivity analyses were carried out for the primary outcome. 
Regarding the fourth manipulation check, results showed that merely rubbing before the application of cowhage in the RHI caused at least some itch in twenty participants (half of them rated itch $\leq 1.0$ ). The average itch score was $0.7 \pm 0.9$ (range 0.0 to 3.3 ), which differed significantly from 0 (logtransformed $t(35)=5.64, p<0.001)$, therefore sensitivity analyses were carried out for the primary outcome.

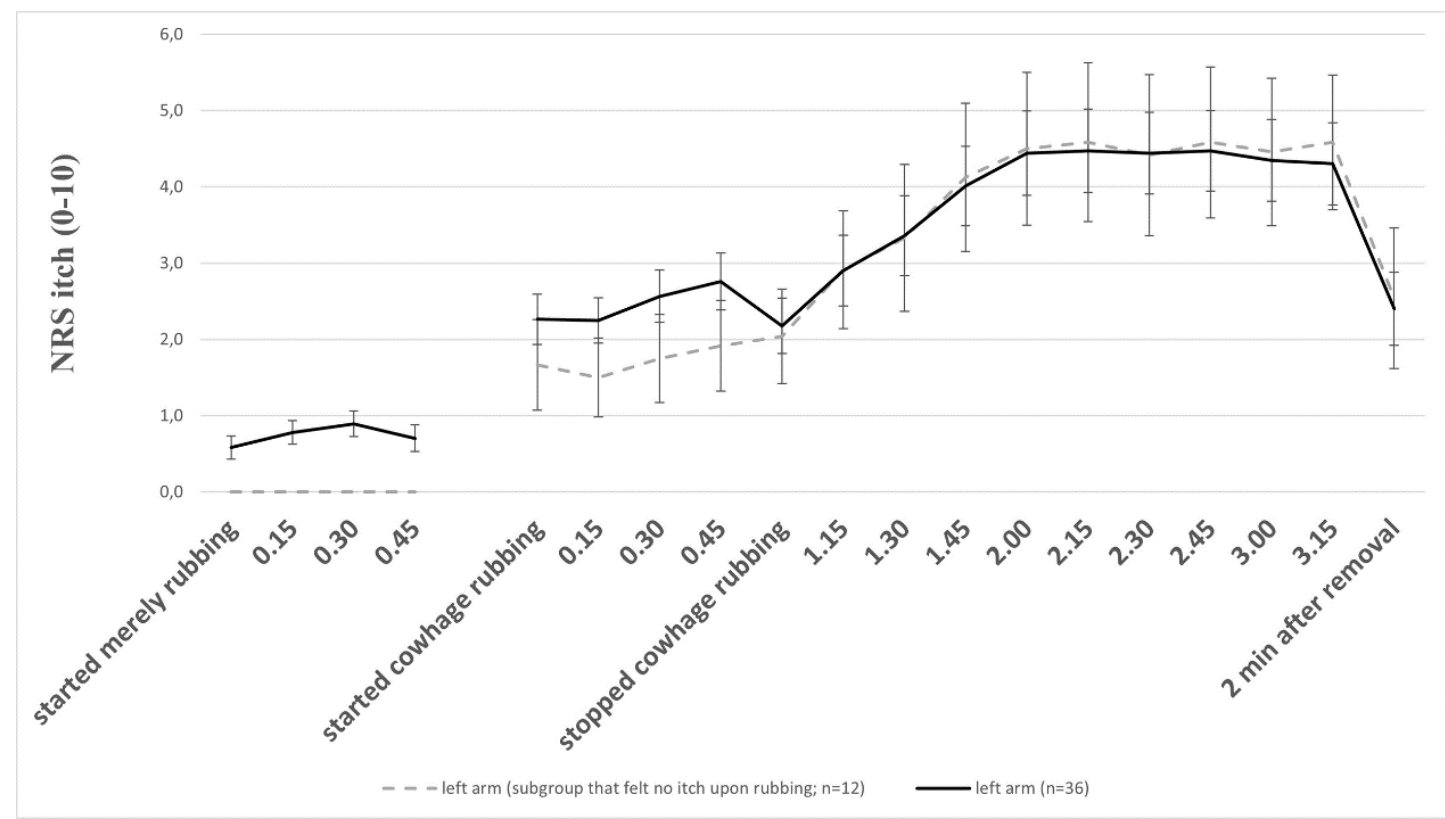

Fig 2. Itch evoked by the baseline cowhage application on the left arm. Time course of the average itch induced by merely rubbing (left part of the graph) and from the rubbing of cowhage, during the follow-up phase with cowhage still being on the arm as well as 2 minutes after cowhage removal ( $n$ $=36$ ).

Table 1 Outcomes of proprioception before the rubber hand illusion (RHI) at $\mathbf{T}_{0}$, right before $\left(T_{1}\right)$ and right after $\left(T_{2}\right)$ the cowhage application on the rubber hand while the participant's concealed hand was merely rubbed

\begin{tabular}{lllll}
\hline & $\begin{array}{l}\text { Position right } \\
\text { index finger }(\mathbf{c m})\end{array}$ & $\begin{array}{l}\text { Perceived position } \\
\text { of right index } \\
\text { finger }(\mathbf{c m})\end{array}$ & $\begin{array}{l}\text { Deviation between } \\
\text { actual and } \\
\text { perceived position } \\
\text { of the right index } \\
\text { finger }(\boldsymbol{\Delta} \mathbf{~ c m})^{\mathbf{2}}\end{array}$ & \\
\hline & & Ownership $^{\mathbf{3}}$ & \\
\hline $\mathbf{T}_{\mathbf{0}}$ & $69.0 \pm 1.8$ & $61.8 \pm 4.5$ & $7.2 \pm 4.8$ & n.a. \\
$\mathbf{T}_{\mathbf{1}}$ & n.a. ${ }^{1}$ & $56.8 \pm 5.6$ & $12.1 \pm 6.0$ & $6.6 \pm 1.9$ \\
$\mathbf{T}_{\mathbf{2}}$ & $67.8 \pm 2.5$ & $56.6 \pm 5.8$ & $11.2 \pm 6.3$ & $6.6 \pm 2.2$ \\
\hline
\end{tabular}

${ }^{1}$ position of right index finger was not assessed since it was assumed identical to $\mathrm{T}_{0}$

${ }^{2}$ Positive values reflect a drift in the direction of the rubber arm.

${ }^{3}$ ownership was measured using the ownership subscale of the embodiment questionnaire, theoretical range $1-10$

\section{Evoked itch and urge to scratch}

The average (primary outcome) and peak (secondary outcome) levels of itch induced by the cowhage application on the rubber arm during the rubbing phase were $0.8 \pm 1.1$ (range 0 to 5.5; see 
Table 3 ) and $1.3 \pm 1.4$ (range 0 to 6.0 ), respectively (see Fig 3). These values significantly differed from 0 as demonstrated by one sample t-tests for the average itch (log-transformed; $t(35)=5.74, p<$ 0.001 ) and peak itch (median 1.0, Interquartile range, IQR, $0.0-2.0$; log-transformed; $t(35)=6.89, p<$ $0.001)$.

The post-hoc paired samples t-test indicated that itch levels were not significantly different when directly comparing merely rubbing and rubbing with the supposed cowhage administration in the RHI (log-transformed; $t(35)=-1.05, p=.301$ ). Secondarily, during the follow-up phase after rubbing (with the supposed presence of cowhage on the skin), results showed that the average itch[logtransformed mean difference: 0.10, SE 0.02; BCa 95\%-CI 0.06-0.14] and the peak itch (logtransformed; $t(35)=6.43, p<0.001)$. significantly differed from 0 . Also, the mean urge to scratch significantly differed from 0 during rubbing and in the follow-up phase [log-transformed mean difference 0.13, SE 0.03; BCa 95\%-CI 0.08-0.20 and log-transformed mean difference 0.06, SE 0.02; BCa 95\%-CI 0.02-0.11, respectively].

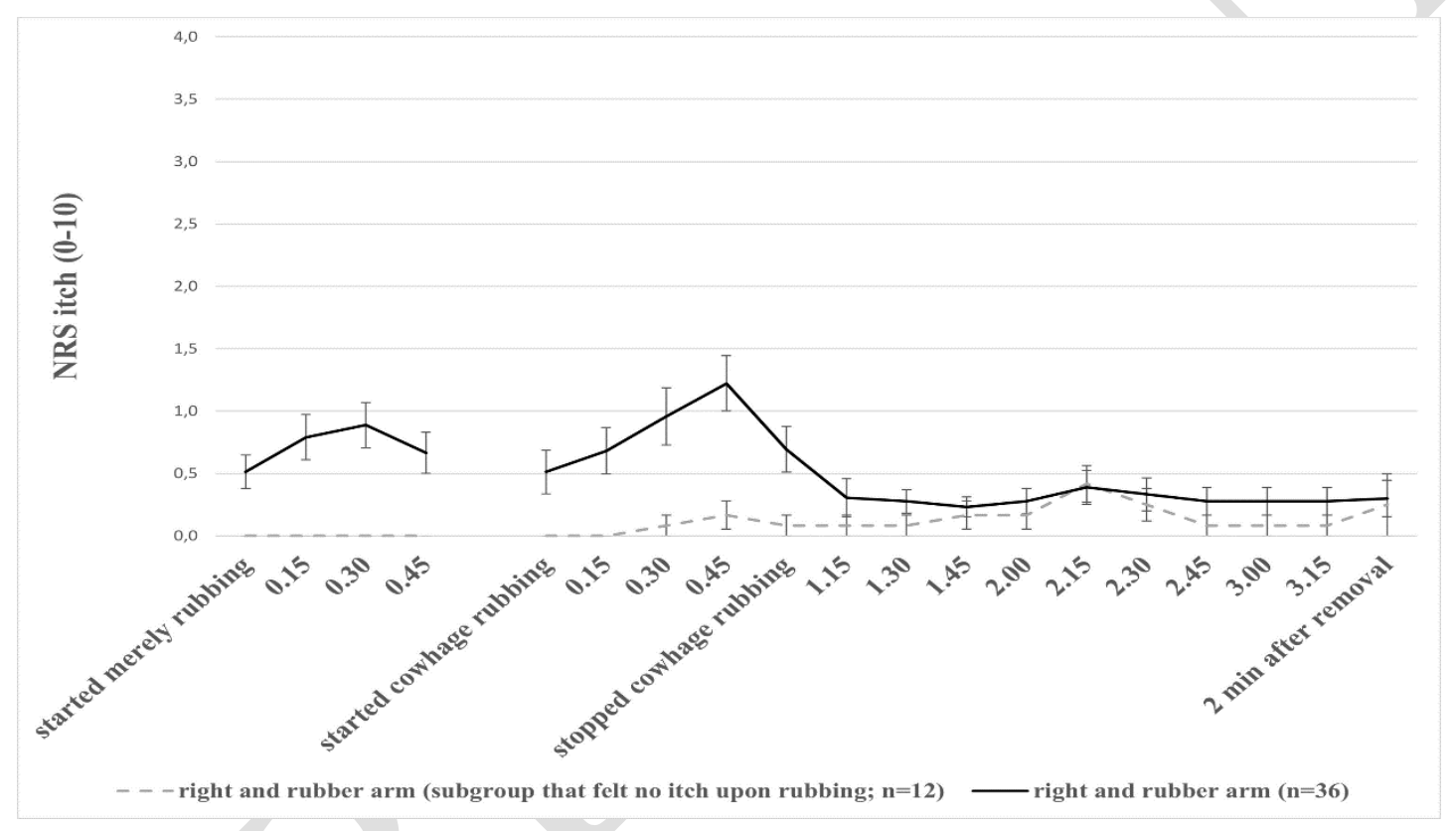

Fig 3. Itch evoked by cowhage application during the RHI. Time course of the average itch induced by merely rubbing (left part of the graph), rubbing of cowhage, during the follow-up phase with cowhage still being on the rubber arm as well as 2 minutes after cowhage removal. The black line represents the entire sample $(n=36)$, the solid grey line represents the sample that felt itch upon merely rubbing $(n=20)$, and the dashed black line represents the part of the sample that did not perceive merely rubbing as itchy $(n=16)$.

Descriptive values for the sensitivity analyses concerning the third manipulation check on ownership are shown in Table 3. Significant itch was induced during both the rubbing phase and the follow-up after rubbing in the RHI for both the participants that were successfully embodied (i.e. ownership subscale $\geq 7.0 ; n=18$ ) to the rubber arm (Bca 95\%-CI $0.10-0.30$ and $0.04-0.16$ respectively; and those that were considered not (i.e. scoring $<7.0$ on the ownership subscale; $n=18$ ) successfully embodied (log-transformed, $t(17)=4.75, p<0.001$ and Bca 95\%-CI 0.05-0.15). These groups (ownership subscale $\geq 7.0 \mathrm{vs}$. $<7.0$ ) did not significantly differ on the average itch induction 
during rubbing (mean difference $0.03, S E=.07$, Bca 95\%-CI -0.12 - 0.16) and during the follow-up (mean difference $-0.01, \mathrm{SE}=.05$, Bca $95 \%$-CI $-0.11-0.08$ ).

Table 3. Means (M), standard deviations (SD), range, median (Mdn) and interquartile range (IQR) of the itch scores during the rubber hand illusion (T2) for the complete sample and the participants that were, according to the ownership subscale of the embodiment questionnaire, successfully embodied (score $\geq 7.0$ ) and those that were not (score $<7.0$ )

\begin{tabular}{|c|c|c|c|c|c|c|c|c|}
\hline & \multicolumn{3}{|c|}{ Total sample } & \multicolumn{3}{|c|}{$\begin{array}{l}\text { Participants who } \\
\text { were successfully } \\
\text { embodied ( } n=18 \text { ) }\end{array}$} & \multicolumn{2}{|c|}{$\begin{array}{l}\text { Participants who were } \\
\text { not successfully } \\
\text { embodied }(n=18)\end{array}$} \\
\hline & $\begin{array}{l}\mathrm{M} \pm \\
\mathrm{SD}\end{array}$ & Range & $\begin{array}{l}\text { Mdn, } \\
\text { IQR }\end{array}$ & $\begin{array}{l}\mathrm{M} \pm \\
\mathrm{SD}\end{array}$ & Range & $\begin{array}{l}\text { Mdn, } \\
\text { IQR }\end{array}$ & $\begin{array}{ll}\mathrm{M} \pm & \text { Range } \\
\mathrm{SD} & \end{array}$ & $\begin{array}{l}\text { Mdn, } \\
\text { IQR }\end{array}$ \\
\hline $\begin{array}{l}\text { Itch }^{1} \text { evoked } \\
\text { during supposed } \\
\text { rubbing of } \\
\text { cowhage }\end{array}$ & $\begin{array}{l}0.8 \pm \\
1.1\end{array}$ & $\begin{array}{l}0- \\
5.5\end{array}$ & $\begin{array}{l}0.4 \\
0.0- \\
1.3\end{array}$ & $\begin{array}{l}0.9 \pm \\
0.3\end{array}$ & $\begin{array}{l}0.0- \\
5.5\end{array}$ & $\begin{array}{l}0.3 \\
0.0\end{array}$ & $\begin{array}{ll}0.8 \pm & 0.0- \\
0.2 & 3.0\end{array}$ & $\begin{array}{l}0.6 \\
0.0- \\
1.3\end{array}$ \\
\hline $\begin{array}{l}\text { Itch }^{1} \text { evoked in } \\
\text { follow-up after } \\
\text { rubbing (cowhage } \\
\text { supposedly } \\
\text { applied) }\end{array}$ & $\begin{array}{l}0.3 \\
\pm 0.6\end{array}$ & $\begin{array}{l}0.0- \\
2.7\end{array}$ & $\begin{array}{l}0.1 \\
0.0- \\
0.4\end{array}$ & $\begin{array}{l}0.4 \pm \\
0.2\end{array}$ & $\begin{array}{l}0.0 \\
2.7\end{array}$ & $\begin{array}{l}0.1, \\
0.0 \\
0.3\end{array}$ & $\begin{array}{l}0.3 \pm \\
0.1\end{array}$ & $\begin{array}{l}0.1 \\
0.0- \\
0.4\end{array}$ \\
\hline
\end{tabular}

Descriptive values for the sensitivity analyses concerning the fourth manipulation check on whether merely rubbing evoked itch are shown in Table 4 . These sensitivity analyses confirmed that significant itch was induced during the illusion for those who did not perceive rubbing as itchy (i.e. with an NRS itch during the merely rubbing phase of $\mathrm{T} 2$ being on average $0.0 ; n=16)$, both during the supposed cowhage rubbing phase [Bca 95\%-CI 0.01-0.06] and during the follow-up after rubbing [Bca 95\%-CI 0.02-0.08]. Unsurprisingly, also those who perceived merely rubbing as itchy (i.e. with an NRS itch during the merely rubbing phase of $\mathrm{T} 2$ being on average $\geq 0.1 ; n=20$ ) showed a significant itch evocation during the rubbing phase of the RHI [Bca 95\%-CI 0.25-0.44] and during the follow-up [Bca 95\%-CI 0.06-0.22]. The post-hoc sensitivity analysis demonstrated that the group that perceived merely rubbing as itchy experienced significantly more itch than the group that did not perceive rubbing as itchy both during the cowhage rubbing phase [mean difference - $0.31, S E 0.05,95 \%$-CI 0.40--0.21] and during the follow-up phase [mean difference -0.09, SE 0.04, 95\%-CI -0.19--0.01]. 
Table 4. Means (M), standard deviations (SD), range, median (Mdn) and interquartile range (IQR) of the itch scores during the rubber hand illusion (T2) for the participants who did not and those who did perceive merely rubbing as itchy

\begin{tabular}{|c|c|c|c|c|c|}
\hline & \multicolumn{3}{|c|}{$\begin{array}{l}\text { Participants who did not } \\
\text { perceive merely rubbing as } \\
\text { itchy }(n=16)\end{array}$} & \multicolumn{2}{|c|}{$\begin{array}{l}\text { Participants who perceived } \\
\text { merely rubbing as itchy }(n=20)\end{array}$} \\
\hline & $\mathrm{M} \pm \mathrm{SD}$ & Range & $\begin{array}{l}\text { Mdn, } \\
\text { IQR }\end{array}$ & $\mathrm{M} \pm \mathrm{SD}$ & $\begin{array}{l}\text { Mdn, } \\
\text { IQR }\end{array}$ \\
\hline $\begin{array}{l}\text { Itch }{ }^{1} \text { evoked during } \\
\text { supposed rubbing of } \\
\text { cowhage }\end{array}$ & $0.1 \pm 0.1$ & $0.0-0.5$ & $\begin{array}{l}0.0 \\
0.0-0.3\end{array}$ & $0.0-5.5$ & $\begin{array}{l}1.3 \\
0.8-1.9\end{array}$ \\
\hline $\begin{array}{l}\text { Itch }^{1} \text { evoked in follow- } \\
\text { up after rubbing } \\
\text { (cowhage supposedly } \\
\text { applied) }\end{array}$ & $0.1 \pm 0.2$ & $0.0-0.5$ & $\begin{array}{l}0.1, \\
0.0-0.2\end{array}$ & $0.5 \pm 0.8$ & $\begin{array}{l}0.3, \\
0.0-0.5\end{array}$ \\
\hline
\end{tabular}

\section{Dot-probe task measuring attentional bias towards itch}

The median \pm interquartile range (IQR) RT for the different trials, while excluding the trials < $150 \mathrm{~ms}$, incorrect trials as well as the trials of the participant that made $>30 \%$ errors, are displayed in Table 5. Overall, the participants did not display an $\mathrm{AB}$ towards the itch pictures, as demonstrated by the dot-position $\mathrm{x}$ itch picture-position interaction of the RM-ANOVA $\left(F(1,34)=1.00, p=0.33, \eta_{\mathrm{p}}{ }^{2}=\right.$ 0.026). There was no significant main effect of the position of the itch pictures $(F(1,34)=1.52, p=$ $\left.0.23, \eta_{\mathrm{p}}{ }^{2}=0.043\right)$, but there was a main effect of dot-position $\left(F(1,34)=17.16, p<0.001, \eta_{\mathrm{p}}{ }^{2}=0.34\right)$ with the Sidak corrected post-hoc comparison indicating that the RT for the dots appearing on the bottom of the screen were slightly, but significantly, longer than the RT for the dots on the top of the screen (mean difference -.01, SE 0.003, 95\%-CI -0.02--0.01). The median reliability of this dot-probe task as assessed by the Spearman-Brown coefficient of 5000 split-half samples was 0.73 (IQR: 0.66$0.78)$.

Table 5. Median (interquartile range; IQR) Reaction time (RT) of the different trial types in the dot-probe task $(n=35)$ measuring attention bias (AB) towards itch

\begin{tabular}{lll}
\hline & Itch picture position upper half & Itch picture position lower half \\
\hline Dot position upper half & $788.67(725.03-884.64)^{1}$ & $739.08(739.08-861.59)^{2}$ \\
Dot position lower half & $808.46(764.47-899.30)^{2}$ & $827.85(758.81-891.76)^{1}$ \\
\hline
\end{tabular}

${ }^{1}$ Congruent trials had a median (IQR) RT of 802.51 (741.99-899.35)

${ }^{2}$ Incongruent trials had a median RT (IQR) RT of 791.63 (748.19-879.61)

\section{Associations between individual characteristics and itch evoked in the RHI}

None of the correlation coefficients between the average levels of itch induced in the RHI and the measures of ownership and proprioceptive drift were significant (all $p>0.25$; see Table 5). 
However, the two measures of embodiment (embodiment and proprioceptive drift) were highly interrelated at $\mathrm{T}_{2}: \rho=0.43, p=0.009$. Self-reported attention to itch (PVAQ-I) as well as cognitive intrusions by itch (ECIP-I), but not $\mathrm{AB}$ towards itch as measured with the dot-probe task nor imagination ability in the cutaneous domain (QMI-cutaneous), correlated significantly with the itch levels evoked in the RHI (Table 5).

Table 5 Pearson's $r$ and Spearman's $r_{s}$ correlation coefficients) between the individual characteristics and itch induced during the rubber hand illusion (RHI) for itch

\begin{tabular}{|c|c|c|}
\hline Individual characteristic & $\begin{array}{c}\text { Average itch induced } \\
\text { in the RHI - during } \\
\text { rubbing }(r)\end{array}$ & $\begin{array}{l}\text { Average itch induced in } \\
\text { the RHI - during follow- } \\
\operatorname{up}\left(r_{s}\right)\end{array}$ \\
\hline Attentional bias $(\mathrm{AB})$ towards itch ${ }^{1}$ & .20 & -.06 \\
\hline Embodiment at $\mathrm{T}_{1}$ & -.17 & -.18 \\
\hline Embodiment at $\mathrm{T}_{2}$ & -.03 & 0.14 \\
\hline Proprioceptive drift $\mathrm{T}_{1}$ & -.02 & -0.003 \\
\hline Proprioceptive drift $\mathrm{T}_{2}$ & -.20 & -0.17 \\
\hline Self-reported attention to itch (PVAQ-I) & .18 & $.37 *$ \\
\hline Cognitive intrusions by itch (ECIP-I) & 25( & .25 \\
\hline $\begin{array}{l}\text { Imaginative ability in the cutaneous domain } \\
\text { (QMI-cutaneous) }\end{array}$ & .10 & .26 \\
\hline
\end{tabular}

The median split dividing the participants in RHI itch-responders $(n=18)$ and RHI itch nonresponders $(n=18)$ did not show significant differences in the levels of AB towards itch (dot-probe task), ownership, proprioceptive drift, distraction during the RHI, identification with the rubber arm, their self-reported attention to itch (PVAQ-I), cognitive intrusions by itch (ECIP-I), nor in imaginative ability (QMI-cutaneous). These groups only differed on basis of the levels of itch induced during the rubbing phase of the baseline cowhage application, with the responders perceiving higher levels of itch than the non-responders $(t(34)=-2.52, p=0.008)$.

\section{Mediating role of expectancies}

The mediation model with the levels of itch during the rubbing phase showed that the baseline cowhage evoked itch (independent variable) significantly predicted the dependent variable of the level of itch during the RHI (direct effect $b=0.24 p=0.03$ ) and the itch expectancy (first part of the indirect effect; $b=0.65 p=0.004$ ), but the expectancies did not predict the outcome of itch during the RHI (second part of the indirect effect; $b=0.07, p=0.33$ ). Hence, the indirect effect was insignificant, $b=0.05$, Bca 95\%-CI [-0.02, 0.12]. The mediation model with the levels of itch during the follow-up phase, with cowhage still on the rubber arm, showed that only the baseline cowhage evoked itch significantly predicted the itch expectancy (first part of the indirect effect; $b=0.71 p<0.001$ ), but not the outcome of itch during the follow-up phase of the RHI (direct effect $b=-0.10, p=0.09$ ). Also, the itch expectancy did not significantly predict, although a tendency towards significance was observed, itch evoked during the RHI $(b=0.12, p=0.06)$. The indirect effect was also non-significant, $b=0.08$, Bca 95\%-CI [-0.02, 0.19]. 


\section{End questions}

Of the participants, $64 \%$ was at least to some degree distracted during the RHI (i.e. $>10 / 100$ on the end question A). Seven participants indicated that this was due to muscle pain in the $\operatorname{arm}(\mathrm{s}), 11$ participants indicated that this was due to itch on another body part, 10 participants were distracted by their thoughts, and two participants had another reason (specifically, numbness in the arms because these had to lay still and due to the fake arm). Participants could overall identify for $64 \% \pm 25 \%$ with the rubber arm, ranging from $11 \%$ to $100 \%$ (question $C$ ). Reasons for suboptimal identification (question D) were mainly related to the rubber arm that differed in skin color $(n=3)$, shape/position $(n$ $=18)$, or size $(n=4)$. Also asynchronous rubbing on rubber arm and real arm $(n=1)$, movements of the rubber arm as a result of rubbing $(n=1)$, length of the nails $(n=1)$, as well as length of the nails and dyes on the rubber arm $(n=1)$ were given as reasons for suboptimal identification. Most participants indicated that they felt (question E) much less itch on the right arm $(n=22)$, or somewhat less itch $(n=7)$ than on the left arm. Four participants indicated that the levels of itch on both arms were equal, 2 participants felt somewhat more itch on the right arm and 1 participant felt much more itch on the right arm as opposed to the left arm. Two participants remarked (question F) before the debriefing that no cowhage had been applied to their arm during the illusion (note, they scored $<0.1$ for itch during the RHI).

\section{Discussion}

This study investigated, using a rubber hand illusion (RHI) paradigm, whether itch could be induced in healthy volunteers via the illusion that itchy plant particles, i.e. cowhage, were applied to their skin. Results demonstrated that participants felt itch during and after rubbing the skin on their arm when being in the belief that cowhage was applied to their skin (in fact it was not). The effects were small, and most pronounced in participants scoring higher on self-reported attention to itch (strikingly, there was no association with the behavioral measure of $\mathrm{AB}$ towards itch). The itch levels in the RHI were not associated with the levels of embodiment to the rubber arm. Although the levels of itch evoked at baseline predicted the evoked itch in the RHI and itch expectancies, these expectations did not significantly mediate the relationship between itch induced by cowhage at baseline and the levels of itch induced during the RHI. Noteworthy, merely rubbing unexpectedly turned out to be itchy in a substantial proportion of the participants, therewith not ruling out that the itch could have been evoked by the act of rubbing. Nevertheless, the RHI also significantly induced itch in the subgroup that did not perceive rubbing as itchy.

Manipulation checks confirmed adequate induction of itch by cowhage and a significant drift of proprioception in the direction of the rubber arm. Moreover, although the average scores on embodiment were comparable to previous research ( ${ }^{33}$; relative to their theoretical scoring range)), only $50 \%$ of the participants were 'embodied' to the rubber arm according to the previously reported cut-off point ${ }^{46}$. This relatively low proportion may be explained by the absence of an asynchronous condition, like is usual in previous research (e.g., ${ }^{22,46,47}$ ). In our setup, participants do not have the possibility to compare the degree of embodiment with another condition. Despite the seemingly better effects on proprioceptive drift than on the self-reported embodiment, there was a fairly high correlation between these outcomes in the current study, even though previous research has indicated that proprioceptive drift and embodiment measures do not necessarily correspond ${ }^{42}$. Nevertheless, neither of the embodiment outcomes were significantly associated with the level of itch experienced in 
the RHI. Importantly, sensitivity analyses indicated that there were no differences in the level of itch evoked when comparing the participants that perceived high versus low ownership.

That merely rubbing caused substantial itch which did not significantly differ from the itch evoked during the rubbing phase of the RHI (post-hoc analysis) was unexpected. This could mean that the itch evoked during the supposed rubbing of cowhage could be explained by the rubbing itself. To investigate whether non-itchy stimuli can be perceived as itchy (parallel to alloknesis) due to cognitive processes, it is important to confirm that the applied stimulus is non-itchy. However, for a subgroup of participants rubbing was not perceived as itchy, who also felt significant itch in both phases of the RHI. Moreover, also in the follow-up phase after discontinuation of rubbing, significant itch was induced in the entire group. All in all, despite that two of the manipulation checks failed, it seems plausible that itch can be evoked using a RHI paradigm.

Although significantly different from 0 , the levels of itch were overall very low, which requires further consideration. As discussed, this may primarily be explained by the suboptimal ownership induction, that may also be traced back to the participants being distracted during the RHI as well as suboptimal identification with the rubber arm. Moreover, the sensation of rubbing with cowhage may have felt slightly different from merely rubbing, i.e. spicules penetrating the skin give a slightly stinging sensation. The absence of the stinging sensation during the RHI may have breached the illusion. Second, the transition from merely rubbing to rubbing with cowhage during the RHI may have not been sufficiently distinct; consequently, participants may have had the expectation that cowhage was already applied during the phases of rubbing without cowhage, which in turn, could have amplified itch sensations at the stage of merely rubbing (i.e. a nocebo effect on itch). A third explanation may lie in the fact that the cowhage application on the real arm induced relatively high levels of itch (3.5/10 on average over the entire sampling period, and stable at ca. 4.4 for about a minute). High itch expectations were induced even by a single encounter with an itch stimulus (in line with previous research in another field ${ }^{38}$ ) as the participants' itch expectancy rating was on average 5.3 out of 10. Given that there was no itch stimulus applied during the RHI phase, there is a large discrepancy between the expectation and what was actually occurring. This may have led to a violation of the participants' expectations, and consequently, reduced nocebo effects on itch ${ }^{12}$. The non-significant mediation by expectancies as well as the large proportion of participants indicating to have felt much less itch during the RHI than during the baseline cowhage application are also in line with this reasoning. Fourth, it has been demonstrated that effective embodiment to a rubber hand can result in analgesia ${ }^{18}$, and perhaps it may also have an antipruritic effect. Finally, there were individual differences in responding to the RHI for itch, and largest effects were found in those that scored higher on attentional focusing on itch. That personal characteristics play a role in the efficacy of the RHI is underlined by previous research indicating that those who are more efficient in attention shifting and score higher on hypnotizability have better results in a $\mathrm{RHI}^{34,50}$. Future studies should also incorporate these concepts.

Optimizing the design may further increase its effectiveness. Even though current findings are promising, effects were mainly based on a small proportion of participants that responded to the manipulation. In future research several steps could be taken. First, the induction of ownership could be augmented by a more extensive procedure, e.g., longer and with different types of instruments. Also tailoring of the appearance of the rubber arm, e.g., the position and shape, to the participant as much as possible could further facilitate identification. Important for an optimal embodiment (or integration of the peripersonal space of the body) is an adequate and congruent integration of multisensory signals, including visual, somatosensory, motor and proprioceptive cues - in accordance with the Multi-Sensory Hypothesis (MSH) ${ }^{20,21}$. To this end, virtual reality techniques may be useful because the possibilities are quite flexible. Third, when studying alloknesis, another means of cowhage 
administration could be used, e.g., by single spicule application ${ }^{32}$, to avoid the act of rubbing as this was considered pruritic in several participants. Fourth, as some participants noticed that no cowhage was being applied during the illusion, the control condition should be improved, e.g., by applying inactive cowhage ${ }^{45}$. This way, the participants will still feel the stinging sensation of the spicules penetrating the skin, but no cowhage-induced itch. It is further recommended to systematically assess if participants felt the itch stimulus being applied. Fifth, the dot-probe task used in the current study was the first to use an itch stimulus display time of $1,250 \mathrm{~ms}$, aiming at studying attentional disengagement. Although the lack of an overall $\mathrm{AB}$ towards itch in our sample is in line with metaanalytic findings of previous pain research using $>1,000 \mathrm{~ms}$ stimulus display time in healthy individuals ${ }^{14,48}$, it could be valuable to further explore the role of individual differences in $A B$ towards itch. It is recommended to also use $\mathrm{AB}$ tasks with shorter display times, with which indications for $\mathrm{AB}$ towards itch were previously found in healthy individual ${ }^{27}$ although not consistently ${ }^{8}$ and study the relationship with the RHI effects. Sixth, several manipulations could be incorporated in the design to test the influence of psychological factors on itch origination and amplification. Examples are expectancy inductions, e.g., giving verbal suggestions that the participants will experience itch upon stimulation of the rubber arm while explicitly instructing when the itch stimulus is applied, and attention manipulations, e.g., instruct participants to either focus on the rubber arm or on a secondary task. Finally, generalization of the findings to the general population could be facilitated by including a more heterogeneous sample in terms of age range, gender, and educational level. With optimized methodology, it would also be worthwhile to include patients with chronic itch to investigate whether they may be more prone to allo- and hyperknesis evoked by cognitive processes. Regularly assessing one's susceptibility to allo- and hyperknesis processes as well as the associated psychological determinants could potentially also provide insight into the progressive course of these processes, which is particularly valuable early after itch diagnoses.

\section{Conclusion}

The current study demonstrated that itch can be induced and increased by use of the RHI paradigm when participants are assuming that an itch stimulus is rubbed onto their arm. The paradigm is thus suitable to study the influence of cognitive processes on itch perception, although more research is needed to optimize the design and to further study the psychological processes that are involved. Gaining a better understanding of the mechanisms behind sensitization processes in patients with chronic pruritus, including the role of psychological processes, is essential to uncover potential targets for (psychological) treatments that are aimed at reducing itch. Moreover, given the indications that the RHI can be used to alleviate pain (e.g., ${ }^{11}$ ), it would be worthwhile to explore whether this setup could also be used for antipruritic purposes. 


\section{Acknowledgements}

The authors would like to thank Renate Heijmans, Nicky van Hunnik, Sophie Jonker, Hyelim Lee, Michelle van Opdorp, and Michelle in ' $t$ Veld for their contribution in data collection. Prof. Ethan Learner is acknowledged for kindly providing the cowhage spicules. Authors are grateful for the help of Maureen Meekel and Evert Dekker with supporting the lab facilities and the dot-probe task. Ralph Rippe is acknowledged for his statistical support. For the dot-probe reliability analyses, we thank Thomas Pronk for giving advice on the methodology and Jennifer M. Becker for her support with the reliability analyses in $\mathrm{R}$.

\section{Funding}

This study was funded by Netherlands Organization for Scientific Research (NWO) 451-15-019 granted to AvL. The funder had no role in study design, data collection and analysis, decision to publish, or preparation of the manuscript.

\section{Conflicts of interest}

The authors have no conflicts of interest to declare. 


\section{References}

[1] Andersen HH, Akiyama T, Nattkemper LA, van Laarhoven A, Elberling J, Yosipovitch G, Arendt-Nielsen L. Alloknesis and hyperknesis - mechanisms, assessment methodology, and clinical implications of itch sensitization. Pain 2018;159:1185-97.

[2] Andersen HH, Elberling J, Sølvsten H, Yosipovitch G, Arendt-Nielsen L. Nonhistaminergic and mechanical itch sensitization in atopic dermatitis. Pain 2017;158:1780-91.

[3] Andersen HH, Sørensen A-KR, Nielsen GAR, Mølgaard MS, Stilling P, Boudreau SA, Elberling J, Arendt-Nielsen L. A Test-retest Reliability Study of Human Experimental Models of Histaminergic and Non-histaminergic Itch. Acta Derm. Venereol. 2017;97:198-207.

[4] Attridge N, Crombez G, Van Ryckeghem D, Keogh E, Eccleston C. The Experience of Cognitive Intrusion of Pain: Scale development and validation. Pain 2015;156:1978-90.

[5] Barnsley N, McAuley JH, Mohan R, Dey A, Thomas P, Moseley GL. The rubber hand illusion increases histamine reactivity in the real arm. Curr. Biol. 2011;21:R945-6.

[6] Bauer A, Hagenburger J, Plank T, Busch V, Greenlee MW. Mechanical pain thresholds and the rubber hand illusion. Front. Psychol. 2018;9:712.

[7] Baum C, Schneider R, Keogh E, Lautenbacher S. Different stages in attentional processing of facial expressions of pain: A dot-probe task modification. J. Pain 2013;14:223-32.

[8] Becker JM, Vreijling SR, Dobbinga S, Giesbers JJJ, Evers AWM, Veldhuijzen DS, Van Laarhoven AIM. Attentional bias towards visual itch and pain stimuli in itch- and pain-free individuals? Acta Derm. Venereol. 2020;100:adv00199.

[9] Blythe JS, Peerdeman KJ, Veldhuijzen DS, van Laarhoven AIM, Evers AWM. Placebo and nocebo effects on itch: a review of experimental methods. Itch 2019;4:e27.

[10] Botvinick M, Cohen JD. Rubber hand 'feels' what eyes see. Nature 1998;391:756.

[11] Coleshill MJ, George DN, Mazzoni G. Placebo Analgesia From a Rubber Hand. J. Pain 2017;18:1067-77.

[12] Colloca L, Schenk LA, Nathan DE, Robinson OJ, Grillon C. When Expectancies Are Violated: A Functional Magnetic Resonance Imaging Study. Clin. Pharmacol. Ther. 2019;106:1246-52.

[13] Computing RF for S. R: A language and environment for statistical computing. version 4.0.3 2019. Available: https://www.r-project.org/.

[14] Crombez G, Van Ryckeghem DML, Eccleston C, Van Damme S. Attentional bias to painrelated information: A meta-analysis. Pain 2013;154:497-510.

[15] Dickison P, Swain G, Peek JJ, Smith SD. Itching for answers: Prevalence and severity of pruritus in psoriasis. Australas. J. Dermatol. 2018;59:206-9.

[16] Van Diest I, Thayer JF, Vandeputte B, Van de Woestijne KP, Van den Bergh O. Anxiety and respiratory variability. Physiol. Behav. 2006;89:189-95.

[17] Ehrsson HH, Wiech K, Weiskopf N, Dolan RJ, Passingham RE. Threatening a rubber hand that you feel is yours elicits a cortical anxiety response. Proc. Natl. Acad. Sci. U.S.A. 2007;104: 9828-33.

[18] Fang W, Zhang R, Zhao Y, Wang L, Zhou Y Di. Attenuation of pain perception induced by the rubber hand illusion. Front. Neurosci. 2019;13:261.

[19] Fortune DG, Richards HL, Corrin A, Taylor RJ, Griffiths CEM, Main CJ. Attentional bias for psoriasis-specific and psychosocial threat in patients with psoriasis. J. Behav. Med. 2003;26:211-24.

[20] Gentile G, Guterstam A, Brozzoli C, Henrik Ehrsson H. Disintegration of multisensory signals 
from the real hand reduces default limb self-attribution: An fMRI study. J. Neurosci. 2013;33:13350-66.

[21] Grivaz P, Blanke O, Serino A. Common and distinct brain regions processing multisensory bodily signals for peripersonal space and body ownership. Neuroimage 2017;147:602-18.

[22] de Haan AM, Van Stralen HE, Smit M, Keizer A, Van der Stigchel S, Dijkerman HC. No consistent cooling of the real hand in the rubber hand illusion. Acta Psychol. 2017;179:68-77.

[23] Hayes AF. An introduction to mediation, moderation, and conditional process analysis: A regression-based approach. 2nd ed. New York: Guilford Press, 2018.

[24] Helmchen C, Palzer C, Münte TF, Anders S, Sprenger A. Itch relief by mirror scratching. A psychophysical study. PLoS One 2013;8:e82756.

[25] Ikoma A, Steinhoff M, Ständer S, Yosipovitch G, Schmelz M. The neurobiology of itch. Nat. Rev. Neurosci. 2006;7:535-47.

[26] van Laarhoven AI, Kraaimaat FW, Wilder-Smith OH, Evers AW. Role of attentional focus on bodily sensations in sensitivity to itch and pain. Acta Derm Venereol 2010;90:46-51.

[27] van Laarhoven AIM, van Damme S, Lavrijsen APM, van Ryckeghem DM, Crombez G, Evers AWM. Attentional processing of itch. Psychol. Res. 2018;82:876-88.

[28] Van Laarhoven AIM, Marker JB, Elberling J, Yosipovitch G, Arendt-Nielsen L, Andersen HH. Itch sensitization? A systematic review of studies using quantitative sensory testing in patients with chronic itch. Pain 2019;160:2661-78.

[29] van Laarhoven AIM, Peerdeman KJ, Van Ryckeghem DML, Evers AWM. Cognitive processing of itch itch pain: The role of attention and expectations. In: Yosipovitch G, Andersen HH, Arendt-Nielsen L, editors. Itch and pain: Similarities, Interactions and Differences. Wolters Kluwer, 2020. pp. 289-98.

[30] Van Laarhoven AIM, Ulrich DJO, Wilder-Smith OH, Van Loey NEE, Nieuwenhuis MA, Van Der Wee NJA, Evers AWM. Psychophysiological processing of itch in patients with chronic post-burn itch: An exploratory study. Acta Derm. Venereol. 2016;96:613-8.

[31] Lakens D. Calculating and reporting effect sizes to facilitate cumulative science: A practical primer for t-tests and ANOVAs. Front. Psychol. 2013;4:863.

[32] LaMotte RH, Shimada SG, Green BG, Zelterman D. Pruritic and nociceptive sensations and dysesthesias from a spicule of cowhage. J. Neurophysiol. 2009;101:1430-43.

[33] Longo MR, Schüür F, Kammers MPM, Tsakiris M, Haggard P. What is embodiment? A psychometric approach. Cognition 2008;107:978-98.

[34] Lush P, Botan V, Scott RB, Seth AK, Ward J, Dienes Z. Trait phenomenological control predicts experience of mirror synaesthesia and the rubber hand illusion. Nat. Commun. 2020;11:4853.

[35] Martini M. Real, rubber or virtual: The vision of "one's own" body as a means for pain modulation. A narrative review. Conscious. Cogn. 2016;43:143-51.

[36] Meeuwis SH, van Middendorp H, van Laarhoven AIM, van Leijenhorst C, Pacheco-Lopez G, Lavrijsen APM, Veldhuijzen DS, Evers AWM. Placebo and nocebo effects for itch and itchrelated immune outcomes: A systematic review of animal and human studies. Neurosci. Biobehav. Rev. 2020;113:325-37.

[37] Mohan R, Jensen KB, Petkova VI, Dey A, Barnsley N, Ingvar M, McAuley JH, Moseley GL, Ehrsson HH. No Pain Relief with the Rubber Hand Illusion. PLoS One 2012;7:e52400.

[38] Morton DL, Brown CA, Watson A, El-Deredy W, Jones AKP. Cognitive changes as a result of a single exposure to placebo. Neuropsychologia 2010;48:1958-64.

[39] Napadow V, Li A, Loggia ML, Kim J, Mawla I, Desbordes G, Schalock PC, Lerner EA, Tran 
TN, Ring J, Rosen BR, Kaptchuk TJ, Pfab F. The imagined itch: Brain circuitry supporting nocebo-induced itch in atopic dermatitis patients. Allergy Eur. J. Allergy Clin. Immunol. 2015;70:1485-92.

[40] Pronk T. Splithalfr: Extensible Bootstrapped Split-Half Reliabilities. version 2.0.12 2020. Available: https://cran.r-project.org/package=splithalfr.

[41] Roelofs J, Peters ML, McCracken L, Vlaeyen JWS. The pain vigilance and awareness questionnaire (PVAQ): Further psychometric evaluation in fibromyalgia and other chronic pain syndromes. Pain 2003;101:299-306.

[42] Rohde M, Luca M, Ernst MO. The rubber hand illusion: Feeling of ownership and proprioceptive drift Do not go hand in hand. PLoS One 2011;6:e21659.

[43] Van Ryckeghem DML, Crombez G, Goubert L, De Houwer J, Onraedt T, Van Damme S. The predictive value of attentional bias towards pain-related information in chronic pain patients: A diary study. Pain 2013;154:468-75.

[44] Sheehan PW. A shortened form of Betts' questionnaire upon mental imagery. J Clin Psychol 1967;23:386-9.

[45] Sikand P, Shimada SG, Green BG, LaMotte RH. Similar itch and nociceptive sensations evoked by punctate cutaneous application of capsaicin, histamine and cowhage. Pain 2009;144:66-75.

[46] Smit M, Brummelman JTH, Keizer A, van der Smagt MJ, Dijkerman HC, van der Ham IJM. Body ownership and the absence of touch: approaching the rubber hand inside and outside perihand space. Exp. Brain Res. 2018;236:3251-65.

[47] Van Stralen HE, van Zandvoort MJE, Hoppenbrouwers SS, Vissers LMG, Kappelle LJ, Dijkerman HC. Affective touch modulates the rubber hand illusion. Cognition 2014;131:14758.

[48] Todd J, van Ryckeghem DML, Sharpe L, Crombez G. Attentional bias to pain-related information: a meta-analysis of dot-probe studies. Health Psychol. Rev. 2018;12:419-36.

[49] Verhoeven EWM, Kraaimaat FW, Van De Kerkhof PCM, Van Weel C, Duller P, Van Der Valk PGM, Van Den Hoogen HJM, Bor JHJ, Schers HJ, Evers AWM. Prevalence of physical symptoms of itch, pain and fatigue in patients with skin diseases in general practice. Br. J. Dermatol. 2007;156:1346-9.

[50] Yeh SL, Lane TJ, Chang AY, Chien SE. Switching to the rubber hand. Front. Psychol. 2017;8:2172.

[51] Yosipovitch G, Andersen HH, Arendt-Nielsen L. Itch and Pain: similarities, Interactions, and Differences. 1st ed. Yosipovitch G, Andersen HH, Arendt-Nielsen L, editors Philadelphia: Wolters Kluwer, 2020. 